\title{
Reversal of hepatic fibrosis: pathophysiological basis of antifibrotic therapies
}

This article was published in the following Dove Press journal:

Hepatic Medicine: Evidence and Research

2 July 2011

Number of times this article has been viewed

\author{
Mona $\mathrm{H}$ Ismail' \\ Massimo Pinzani² \\ 'Department of Internal Medicine, \\ Division of Gastroenterology, King \\ Fahad University Hospital, Al-Khobar, \\ Saudi Arabia; ${ }^{2}$ Dipartimento di \\ Medicina Interna Center for \\ Research, High Education and Transfer, \\ Università degli Studi di Firenze, \\ Florence, Italy
}

\begin{abstract}
Chronic liver injuries of different etiologies eventually lead to fibrosis, a scarring process associated with increased and altered deposition of extracellular matrix in the liver. Progression of fibrosis has a major worldwide clinical impact due to the high number of patients affected by chronic liver disease which can lead to severe complications, expensive treatment, a possible need for liver transplantation, and death. Liver fibrogenesis is characterized by activation of hepatic stellate cells and other extracellular matrix producing cells. Liver fibrosis may regress following specific therapeutic interventions. Other than removing agents causing chronic liver damage, no antifibrotic drug is currently available in clinical practice. The extent of liver fibrosis is variable between individuals, even after controlling for exogenous factors. Thus, host genetic factors are considered to play an important role in the process of liver scarring. Until recently it was believed that this process was irreversible. However, emerging experimental and clinical evidence is starting to show that even cirrhosis in its early stages is potentially reversible.
\end{abstract}

Keywords: liver fibrosis, cirrhosis, fibrogenesis, antifibrotic agents

\section{Introduction}

Chronic liver disease is a major cause of mortality and morbidity worldwide. Most chronic liver diseases progress from mild inflammation to more severe inflammation, leading to fibrosis or cirrhosis. This can result in liver failure and portal hypertension, and is associated with an increased risk of liver cancer. ${ }^{1}$ The development of advanced fibrosis, and particularly cirrhosis, is associated with significant and life-threatening complications, with liver transplantation being the only available treatment. However, transplantation is not always possible, due to limited organ availability and the presence of contraindicating comorbidities.

Fibrosis is a progressive pathological process in which the body's wound healing and tissue remodeling mechanisms respond to liver injury by promoting replacement of normal hepatic tissue with a scar-like matrix composed of cross-linked collagen. ${ }^{2}$ Until recently, it was believed that this process was irreversible. ${ }^{3}$ However, emerging experimental and clinical evidence is starting to show that even early stages of cirrhosis are potentially reversible.

The cascade of events leading to hepatic fibrosis is complex, and is influenced by how different cell types in the liver interact in response to injury. The main cell type responsible for the development of fibrosis in chronic liver disease is the activated hepatic stellate cell. Chronically activated hepatic stellate cells proliferate and synthesize extracellular matrix proteins to produce the fibrous scar (Figure 1). ${ }^{4}$
Correspondence: Mona $\mathrm{H}$ Ismail of Dammam, Department of Internal Medicine, Division of Gastroenterology, King Fahad Hospital, PO Box 40I49, Al-Khobar 31952, Saudi Arabia Tel +9663896674 I

Fax +96638966741

Email mismail.md@gmail.com 


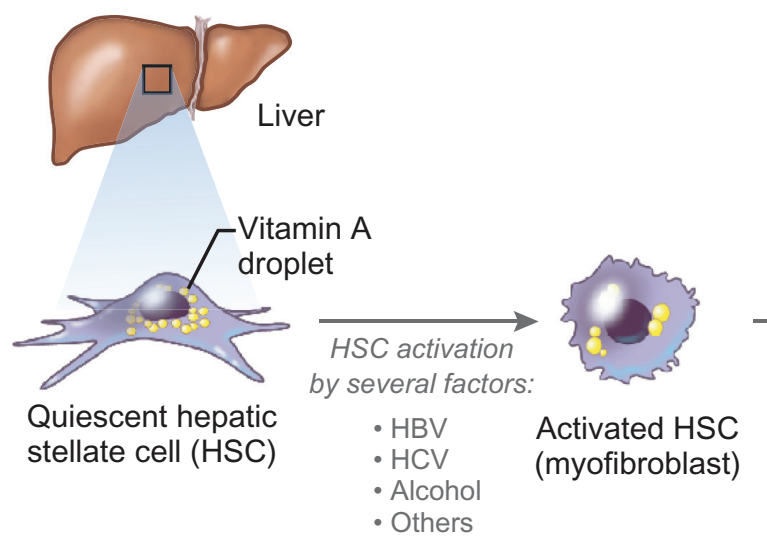

Following any type of liver injury, hepatic stellate cells differentiate into myofibroblasts and acquire the typical "myofibroblast-like" phenotype characterized by a multifunctional profibrogenic, proinflammatory, and proangiogenic profile. Reported phenotypic changes garnered from hepatic stellate cell culture studies include increased proliferation, increased expression levels of platelet-derived growth factor- $\beta$ and smooth muscle $\alpha$-actin ( $\alpha$-SMA), and enhanced collagen secretion. ${ }^{5-8}$ More recent evidence implicates a role for leptin in hepatic stellate cell transdifferentiation by activating the hedgehog pathway, and galectin-3 for hepatic stellate cell activation in vivo.,

In addition to hepatic stellate cells, other resident liver mesenchymal cells, such as portal fibroblasts and myofibroblasts, contribute to hepatic fibrogenesis, particularly in chronic liver diseases characterized by primary involvement of the portal and periportal areas (ie, chronic viral hepatitis and cholestatic diseases). ${ }^{11}$

There is some evidence that bone marrow-derived fibrocytes or circulating mesenchymal cells can migrate through the injured liver and become myofibroblasts, which participate in the fibrotic process. ${ }^{12,13}$ In addition, there is controversial evidence that hepatocytes and cholangiocytes may undergo epithelial-mesenchymal transition to become activated myofibroblasts. ${ }^{14}$ Likewise, phenotypic agility associated with epithelial-mesenchymal transition allows for the reverse process whereby mesenchymal cells convert into epithelial derivatives. ${ }^{14}$
Among the three types of proposed epithelialmesenchymal transitions, type 2 epithelial-mesenchymal transition refers to the process occurring in chronic fibrogenic disorders. In the context of fibrogenesis, synthesis and deposition of type I collagens most appropriately signal myofibroblast function in vivo. ${ }^{14}$ However, despite in vitro evidence supporting $1 \alpha 1$ gene activation in cultured epithelial cells, including hepatocytes, these cells fail to generate collagen $1 \alpha 1$ transcripts in vivo. ${ }^{14-16}$ In addition, some cells, particularly macrophages, internalize the collagen fibrillar extracellular matrix that leads to mistaken association of collagen accumulation with collagen synthesis. These contradictions beg the question of whether epithelial cells really play a role in fibrogenesis. ${ }^{14,15,17-19}$

Many cellular markers have been wrongly defined as myofibroblast-specific based on gene expression patterns. For example, certain hepatocytes and cholangiocytes express "mesenchymal markers" typical of cell motility and survival. Hepatocytes when cultured in vitro and chronically stimulated with transforming growth factor- $\beta 1$ or serum factors exhibit genetic expression patterns analogous to myofibroblasts in vivo and connective tissue at the development stage. ${ }^{14,20-24}$ Some of the genes expressed include $\alpha$-SMA, Slug, Twist, Snail, vimentin, and fibroblast-specific protein implicated in cell motility in general, although these genes do not mark myofibroblast or epithelial cell lineages specifically. ${ }^{14,15,18,25-28}$ 
Oddly, $\alpha$-SMA, that forms part of the cell's contractile machinery, constitutes a poor lineage marker for fibrogenesis, although it is the most widely used marker for recognizing myofibroblasts. Activation of this protein expression during disease or as part of an adaptive response to injury, compounded by the fact that it contributes minimally, if at all, to the synthesis and deposition of fibrillar extracellular matrix, explains the ambiguous role of $\alpha$-SMA in marking myofibroblastic activity. ${ }^{14}$

A direct contribution of cholangiocytes to fibrosis via an epithelial-mesenchymal transition pathway has been proposed by Omenetti et al who demonstrated that immature cholangiocytes undergo a complete epithelial-mesenchymal transition when treated with activated hepatic stellate cell medium. ${ }^{29}$ Others have shown coexpression of epithelial and mesenchymal markers in human liver cholangiocytes extracted from patients with cholestatic disease. ${ }^{30,31}$ However, recent reports have challenged the concept of cholangiocyte epithelial-mesenchymal transition, with conclusions pointing towards an absence of this process in liver fibrosis models. ${ }^{32}$ Specifically, fluorescently labeled cholangiocytes expressing the bile ductular cell-specific marker, K19, failed to coexpress myofibroblast markers in either bile duct-ligated or CCL4-induced fibrosis mouse models. ${ }^{33}$ Clearly, further explorations beyond intuitive speculation are needed to unravel the role of epithelial cells and cholangioctyes in fibrogenesis, if any.

The development of significant tissue fibrosis usually requires several years of ongoing insult. However, not all patients exposed to a similar causal agent develop the same degree of liver fibrosis, ie, patients with similar risk factors have some variability in progression of liver fibrosis, which also may reflect host genotypic polymorphisms. ${ }^{33}$ Evidence of fibrotic regression has now been documented in the entire spectrum of chronic liver diseases, including autoimmune hepatitis, biliary obstruction, iron overload, nonalcoholic steatohepatitis, ${ }^{34}$ and viral hepatitis B (HBV) and $\mathrm{C}(\mathrm{HCV}){ }^{35,36}$

Patterns of fibrosis progression have been described on the basis of their disease origin. Among the contributors, chronic HCV poses a significant risk for developing fibrotic tissue, but only becomes lethal following cirrhosis onset. Factors affecting the rate of fibrosis progression in HCVinfected patients include duration of infection, age, male gender, consumption of alcohol, human immunodeficiency (HIV) coinfection, and low CD4 count. ${ }^{37-41}$ Metabolic conditions, including obesity, steatosis, and diabetes, are also surfacing as independent risk factors. ${ }^{42}$
Both male gender and age strongly influence the speed of disease transition from infection to cirrhosis, with a 300 fold higher progression rate seen in men aged $61-70$ years versus those 20-40 years of age. ${ }^{41}$ In contrast, HCV-infected women progress to cirrhosis at a much slower rate compared with their male counterparts, regardless of age. A multicenter study aimed at evaluating the natural history of liver fibrosis progression in $\mathrm{HCV}$ and associated risk factors reported a median 39\% higher annual rate of fibrosis progression in men compared with women. ${ }^{43}$ The significance of this result was partially rationalized by the greater alcohol consumption associated with men in this trial.

Antifibrotic effects from estrogen may also explain the fibrosis progression disparity seen between the genders. Long-term estrogen exposure reduced liver fibrosis progression in HCV-infected women who had either been pregnant, taken oral contraceptives, or received hormone replacement therapy in one retrospective study conducted across two centers in France. ${ }^{44}$ Infected postmenopausal women not receiving hormone replacement therapy showed the highest rate of fibrosis progression. ${ }^{44}$

Some speculative data have emerged demonstrating a correlation between insulin resistance and increased rate of fibrosis progression in nondiabetic individuals infected with chronic HCV, although a longitudinal study is needed to confirm this interesting observation. ${ }^{45}$

Patients coinfected with HIV and HCV have more rapid progression of cirrhosis that may be partially curbed with highly active antiretroviral therapies. ${ }^{46-50}$ In a recent study, Berenguer et al examined the effects of exposing coinfected patients to nonnucleoside reverse transcriptase inhibitor and protease inhibitor therapy, and reported a successful outcome in reducing fibrosis progression with nonnucleoside reverse transcriptase inhibitors but not with protease inhibitors. ${ }^{46}$

Other special populations on the radar for developing fibrosis-related complications include those with hemochromatosis or nonalcoholic steatohepatitis. Cirrhotic patients with nonalcoholic steatohepatitis have a reduced life expectancy and a concomitant $67 \%$ 5-year survival rate. ${ }^{51,52}$ Evaluation of pooled data from histological studies identified inflammation on the initial biopsy and age as independent predictors of progression of fibrosis to advanced nonalcoholic steatohepatitis. $^{52}$

Individuals suffering from hemochromatosis, characterized by iron deposition within tissues and related end-organ damage, develop cirrhosis, which may or may not present with symptoms or elevated liver enzymes. ${ }^{53-55}$ Some important risk factors identified for increased rate 
of progression of fibrosis in this patient population include alcohol consumption, hepatic steatosis, HCV coinfection, male gender, oxidative injury, and genetic polymorphisms, particularly implicating transforming growth factor- $\beta 1$, tumor necrosis factor- $\beta$, and MCP $1 .{ }^{53}$

Although there is no doubt that liver tissue fibrosis can regress, the issue of regression/reversibility of cirrhosis is controversial and requires considerable clarification. This is particularly relevant after several claims of "cirrhosis reversal" in patients with chronic $\mathrm{HBV}$ and $\mathrm{HCV}$ infection after antiviral treatment. ${ }^{35,56}$ The concept of cirrhosis reversibility originates from evidence obtained in animal models upon the discontinuation of the cause of liver damage or following treatment with antifibrotic agents. Although cirrhosis tends to be defined as one stage, it is quite evident, both morphologically and clinically, that there are several stages of evolution following the initial morphological evidence of cirrhotic transformation of liver tissue. "Early" cirrhosis is often macronodular, with a limited thickness of fibrotic septa and a scarcity of neoangiogenesis. In addition, at this stage, the fibrotic tissue is still characterized by the presence of profibrogenic cells and an abundant inflammatory infiltrate. The evolution of this picture is characterized by increased thickness of the septa that become progressively acellular and by the development of micronodular cirrhosis. From the biochemical point of view, collagen fibers undergo extensive crosslinking and are wrapped in filaments of elastin. At this advanced stage, fibrosis becomes largely irreversible. Therefore, claims of "cirrhosis reversal" need to be framed in the stage of evolution of a cirrhotic liver and the term "reversal" used to denote a return to near-normal liver structure.

Establishing cirrhosis reversal in humans has been hampered by a lack of supportive evidence, compounded by the fact that few relevant experiments were carried out using animal models. ${ }^{57,58}$ It should be stressed that in the large majority of the available animal models (mostly in rodents), cirrhosis develops within weeks and is rather different both in morphological and biochemical (ie, composition and three-dimensional arrangement) terms from the cirrhosis observed in chronically ill patients who develop liver disease over several decades.

\section{Mechanisms of fibrosis reversal}

The first documented evidence for the reversal of liver fibrosis derived from studies showing a progressive decrease of fibrosis associated with apoptosis of hepatic stellate cells in rat models of chronic intoxication with $\mathrm{CCl}_{4}$ following suspension of toxic and bile duct ligation after recanalization of the bile duct. ${ }^{59,60}$ Altogether, these studies suggested that apoptosis of hepatic stellate cells plays a critical role in the recovery from biliary as well as toxic-induced liver fibrosis. In addition, hepatic stellate cell survival and apoptosis are regulated by growth factors expressed during fibrotic liver injury. Issa et $\mathrm{al}^{58}$ went further to show that reversal was obtained in a chronic $\mathrm{CCl}_{4}$ model, even when an advanced stage of micronodular cirrhosis was obtained after 12 weeks of administration of $\mathrm{CCl}_{4}$. Indeed, 1 year after the cessation of administration of $\mathrm{CCl}_{4}$, micronodular cirrhosis underwent remodeling to macronodular cirrhosis. In addition, expression of collagen type 1 and tissue inhibitor of metalloproteinases 1 (TIMP-1) mRNA decreased significantly, and active metalloproteinases were shown in liver tissue during fibrosis remodeling. This was paralleled by a significant loss of more recently formed fibrils, decreased perisinusoidal fibrosis, and decreased thickness of fibrotic septa. Once again, resolution was characterized by apoptosis of hepatic stellate cells, predominantly at the edges of fibrotic septa. Residual septa, not remodeled after 1 year, were characterized by transglutaminase-mediated crosslinking and relative hypocellularity. This experimental study highlighted a limited potential for the cirrhotic liver to engage in spontaneous regression of the mature matrix in the absence of a therapeutic intervention. ${ }^{57,58}$

The relationship between fibrosis reversal and hepatic stellate cell apoptosis highlighted by these studies in animal models suggested that induction of hepatic stellate cell apoptosis could represent a potential antifibrogenic target. This process would necessarily remove the primary hepatic source of newly synthesized collagens as well as TIMP-1. ${ }^{61}$ Hepatic TIMP-1 inhibits metalloproteinases implicated in matrix degradation, and both collagen and TIMP-1 promote myofibroblast survival. ${ }^{62,63}$ Reverse differentiation of the myofibroblasts back to their original phenotype occurs in vitro and therefore constitutes an alternative mechanism for fibrosis regression, although as yet there is no in vivo evidence supporting this claim. ${ }^{57,64,65}$ In fact, Kim et al reported decreases in desmin-positive cells in rats recovering from dimethylnitrosamine-induced fibrosis. ${ }^{66}$ This result argues for the apoptotic pathway because desmin marks both activated myofibroblasts and their hepatic stellate cell precursors. ${ }^{66}$

However, the concept of hepatic stellate cell apoptosis in animal models is not likely to be completely reproducible in the human setting. Despite what we have learned about antifibrotic mechanisms from animal studies, the evidence is at best speculative and needs further support particularly with relevance to 
clinical evidence. Although apoptosis seems to play a role in fibrosis regression, it may simply represent a symptom of extracellular matrix remodeling. This explanation garners validity from experimental evidence showing that expression levels of both collagen 1 and TIMP-1 ramp up during fibrogenesis, but then decrease in the recovering injured liver. ${ }^{57,63,67}$

Different studies performed in human hepatic stellate cells and in liver tissue obtained from patients with chronic viral hepatitis have suggested that human profibrogenic cells, and particularly hepatic stellate cells, are characterized by a resistance to apoptosis once activated and fully involved in the fibrogenic process. ${ }^{68,69}$ It is therefore plausible that long-term fibrogenesis is characterized, in addition to biochemical evolution of scar tissue and lack of an appropriate degradation machinery, by the immovability of a critical mass of profibrogenic cells.

An important aspect of macrophage biology in the fibrogenic process is the observation that these cells are required for fibrosis resolution after withdrawal of the damaging agent. Along these lines, selective depletion of macrophages resulted in reduced scarring and a lower number of fibrogenic cells in the active phase of fibrogenesis, as expected based on previous work..$^{70}$ However, macrophage depletion during fibrosis resolution was associated with delayed matrix degradation. These data indicate the existence of distinct subpopulations of macrophages and the role of these cells in the recovery phase of the fibrogenic process. These data have been recently expanded with the observation that scar-associated macrophages that mediate fibrosis resolution express matrix metallopeptidase 13 allowing them to degrade complex extracellular matrices and remodeling of scar. ${ }^{71}$ The interaction between the chemokine system and macrophages in the process leading to fibrosis resolution has also been recently investigated. When chronically intoxicated with $\mathrm{CCl}_{4}$, mice lacking chemokine (C-C motif) receptor 2 (CCR2) showed lower levels of fibrosis compared with wild-type animals, and reduced $\mathrm{F} 4 / 80+, \mathrm{CD} 11 \mathrm{~b}+$, and CD11c+ populations at the sites of injury. ${ }^{72}$ However, upon discontinuation of toxin administration, fibrosis persisted in CCR2 knockout mice, and was correlated with sustained expression of TIMP-1 and with reduction in matrix metallopeptidase 13 expression. These data suggest that this chemokine system is one of the molecular effectors of both macrophage recruitment during active fibrogenesis and of macrophagedependent fibrosis resolution. Accordingly, because therapies that interfere with chemokines or their receptors are being developed, it may be speculated that a therapy interfering with CCR2 could possibly retard the regression of fibrosis, especially when associated with a strategy that reduces the extent of damage.

\section{Clinical evidence for reversal}

Accordingly, when performing an accurate analysis of results of the clinical studies claiming reversal of cirrhosis after antiviral treatment, the only prudent conclusion is that, in most cases, there was a variable degree of fibrosis regression in cirrhosis but not a reversal of cirrhosis. ${ }^{73,74}$ For example, Poynard et al reported fibrosis reduction among cirrhotic patients with chronic $\mathrm{HCV}$ who received pegylatedinterferon (IFN) and ribavirin regimens. ${ }^{75}$ Of the 153 patients enrolled in their study, 49\% showed downstaging of liver fibrosis from stage 4 to stage 3. A separate study looked retrospectively at liver improvements in 113 individuals with confirmed hepatic cirrhosis and receiving immunosuppressive therapies, including IFN- $\alpha$, or a combination of IFN- $\alpha$ and ribavirin in the case of viral hepatitis infection, or steroids plus azathioprine in autoimmune patients. Among the 113 participants, $14(12.4 \%)$ had biopsy-proven disappearance of cirrhosis. ${ }^{76}$ One rare report describing spontaneous recovery in two young men who had developed HBV-related cirrhosis as children recently emerged. The investigators attributed their "cure" to cessation of viral replication. ${ }^{77}$

Although fibrosis seems to be a reversible process accompanied by regression of scar tissue, establishing clear remodeling or an apoptotic mechanism underlying the regression process remains an elusive goal. However, the more challenging goal of reversing cirrhosis must take into account features other than simple regression alone. Additional factors, including what effects rapid clearance of the matrix would have on the highly altered vasculature structure of the cirrhotic liver, warrants special consideration. ${ }^{13,74,78}$ The availability of improved diagnostic techniques for monitoring disease progression should also enhance the evaluation of potential antifibrotic therapeutics in the clinic. ${ }^{79}$

In other words, fibrotic deposition related to recent disease and characterized by the presence of thin reticulin fibers, often in the presence of a diffuse inflammatory infiltrate, is likely to be fully reversible, whereas longstanding fibrosis, characterized by extensive collagen crosslinking in a dense acellular/ paucicellular extracellular matrix and decreased expression and/or activity of specific metalloproteinases, is not. ${ }^{58,80}$

\section{Assessment of fibrosis regression}

Assessment of the fibrotic evolution of chronic liver disease has relied and still largely relies on histopathological scoring of liver tissue obtained by liver biopsy. However, liver biopsy is an invasive procedure limited by issues relating to sampling, cost, and morbidity, and only provides a static 
measure of fibrosis. It was evident that liver biopsy was an imperfect gold standard when it was used to assess the extent of disease progression in terms of fibrotic transformation of liver tissue, and even more so when the fibrotic stage derived from histopathological evaluation was used as a gold standard to define the diagnostic accuracy of noninvasive methods. ${ }^{81}$ It is increasingly clear that the diagnostic accuracy of liver biopsy is limited by two major caveats, ie, sampling error and interobserver variation among pathologists, with an average $20 \%$ error rate in assessment of fibrosis stage..$^{82,83}$

Alternative methods to quantify liver tissue, such as computer-aided morphometric image analysis of hepatic collagen, ${ }^{84}$ can provide an objective measurement of the proportion of liver with fibrous tissue. By comparison, routine histological assessment also takes into account other subjective factors, such as architectural distortion or nodule formation, but is clearly dependent upon the experience of the individual pathologist. ${ }^{85}$ The coefficient of variation for image analysis compared with standard histological assessment remains unacceptably high, even for $25 \mathrm{~mm}$ biopsies. ${ }^{82}$ In addition, liver biopsy is not practical for monitoring disease progression or response to therapy in chronic HCV infection. ${ }^{86}$ Thus, there is a need for noninvasive tests to assess liver fibrosis. Ideally these tests should be simple, readily available, inexpensive, and accurate. Over past years, several noninvasive tests have become available to assess liver fibrosis. In general terms, these are either "direct markers", ie, proteins derived from the extracellular matrix assembly and remodeling, or "indirect markers" that are in general represented by algorithms, including biochemical tests that are commonly altered in chronic liver disease. ${ }^{87}$

This decline in the diagnostic relevance of liver biopsy, particularly in chronic $\mathrm{HCV}$, has led to the development of noninvasive methodologies for assessment of liver fibrosis or cirrhosis. There are two critical endpoints, ie, the presence of significant fibrosis, which is an indication for antiviral treatment in chronic $\mathrm{HBV}$ and $\mathrm{HCV}$, and the presence of cirrhosis, which is an indication for specific monitoring of complications related to portal hypertension and to the increased risk of developing hepatocellular carcinoma. A summary of the more widely applied diagnostic techniques for evaluating stage of fibrosis are presented in Table 1.

The most commonly used noninvasive methods are measurement of liver stiffness using transient elastography (Fibroscan ${ }^{\circledR}$, Echosens, Paris, France $)^{88}$ and serum biomarkers of fibrosis, eg, the patented FibroTest algorithm. ${ }^{36}$ Various noninvasive markers have been developed to differentiate mild from moderate-to-advanced stage disease, mainly in $\mathrm{HCV}$, but the most widely used and validated with transient elastography ${ }^{88}$ by far are the aspartate to platelet ratio index (APRI, a free nonpatented index ${ }^{89}$ ) and the FibroTest. ${ }^{90}$

The APRI index has also been validated as a fibrosis predictor in HIV coinfection and chronic HCV, and also in alcoholic liver disease. ${ }^{91,92}$ A meta-analysis of 22 studies (most in chronic HCV) shows that, at an APRI threshold of 0.5 , the sensitivity and specificity for significant fibrosis have been $81 \%$ and $50 \%$, respectively, and that, at an APRI threshold of 1.0, the sensitivity and specificity for predicting cirrhosis have been $76 \%$ and $71 \%$, respectively. ${ }^{93}$

Other popular biochemical tests include the Forns' fibrosis index ${ }^{94}$ and Enhanced Liver Fibrosis score. ${ }^{95}$ The diagnostic performance of these indices is generally good, with a receiver-operating characteristic (ROC) curve ranging from 0.77 to 0.88 . Comparative studies have noted that the performance characteristics of these biomarker panels are similar. ${ }^{96,97}$

Imaging techniques are an attractive way of evaluating fibrosis. They have the advantages of being noninvasive and being able to detect structural changes, which serologicalbased tests of fibrosis and inflammation are unable to do. Using the modalities of ultrasound, computed tomography, or magnetic resonance imaging, it is possible to diagnose features of advanced chronic liver disease by recognizing surrogate markers of portal hypertension with a high degree of sensitivity and specificity. However, these techniques do not reliably detect lesser degrees of fibrosis.

Transient elastography has recently become available, which measures liver stiffness or elasticity to assess liver fibrosis. ${ }^{98}$ The scan was developed on the principle that livers with increasing degrees of scarring or fibrosis have decreasing elasticity and that a shear wave propagating through stiffer material would progress faster than in one with more elastic material. ${ }^{99}$ Although the reproducibility of transient elastography has been shown to be excellent in terms of interobserver and intraobserver agreement, ${ }^{40}$ its applicability may not be as good as that of biomarkers. ${ }^{100}$ The principal reasons are obesity, particularly increased waist circumference, and limited operator experience. The risk of overestimating liver stiffness values has been reported in the case of alanine aminotransferase flares in patients with acute viral hepatitis or chronic $\mathrm{HBV},{ }^{101-103}$ as well as in cases of extrahepatic cholestasis ${ }^{104}$ and congestive heart failure. ${ }^{105}$

Initial studies of noninvasive markers largely consisted of single components, but the field has evolved into combining these single components into panel markers. 
Table I Common tests for evaluating liver fibrosis ${ }^{79,81,99,138-140}$

\begin{tabular}{|c|c|c|}
\hline Method & Measures & Advantage/Disadvantages \\
\hline \multicolumn{3}{|l|}{ Biopsy } \\
\hline METAVIR & $\begin{array}{l}\text { Necroinflammation + fibrosis histological score: } \\
\text { F0, no fibrosis } \\
\text { FI, stellate enlargement of the portal tract without septa } \\
\text { F2, stellate enlargement of the portal tract with septa } \\
\text { F3, fibrosis without cirrhosis } \\
\text { F4, cirrhosis }\end{array}$ & $\begin{array}{l}\text { - Necessary for diagnosing autoimmune } \\
\text { hepatitis, primary biliary cirrhosis, NASH, } \\
\text { and Wilson's disease } \\
\text { - Staging and grading for viral hepatitis and } \\
\text { hemochromatosis } \\
\text { - Invasive; patient may experience pain or }\end{array}$ \\
\hline HAl & $\begin{array}{l}\text { Summation of periportal/bridging necrosis, } \\
\text { intralobular degeneration, portal inflammation } \\
\text { and fibrosis (range } 0-22 \text { ) }\end{array}$ & $\begin{array}{l}\text { bleeding and rarely death } \\
\text { - Small sample size, may miss cirrhosis } \\
\text { - Expensive }\end{array}$ \\
\hline \multicolumn{3}{|c|}{ Noninvasive tests (panel) } \\
\hline Fibrotest & $\begin{array}{l}\text { Bilirubin, } \alpha 2-M C \text {, gamma GT, haptoglobin, } \\
\text { Apolipoprotein AI, age and gender } \\
\text { AUC: } t=0.84, v=0.87\end{array}$ & $\begin{array}{l}\text { - Separate mild from severe fibrosis with high } \\
\text { diagnostic accuracy } \\
\text { - Noninvasive }\end{array}$ \\
\hline APRI & $\begin{array}{l}\text { Platelets, AST } \\
\text { AUC: } \mathrm{t}=0.80, \mathrm{v}=0.90\end{array}$ & $\begin{array}{l}\text { - Simplistic and good alternative when biopsy } \\
\text { is contraindicated }\end{array}$ \\
\hline Forns' fibrosis index & $\begin{array}{l}\text { Cholesterol, gamma GT, platelets, and age } \\
\text { AUC: } \mathrm{t}=0.86, v=0.8 \mathrm{I}\end{array}$ & $\begin{array}{l}\text { - Serial measurements possible } \\
\text { - Limitations in evaluating inflammation (biopsy }\end{array}$ \\
\hline Fibrosis probability index & $\begin{array}{l}\text { Plasma glucose, insulin, age at biopsy, } \\
\text { AST, HOMA-IR, total cholesterol and past alcohol } \\
\text { AUC: } t=0.84, v=0.77\end{array}$ & better) \\
\hline Transient elastography & & \\
\hline FibroScan $^{\circledast}$ & $\begin{array}{l}\text { Liver stiffness range } 2.5-75.0 \mathrm{kPa} \text { (normal } 5.5 \mathrm{kPa} \text { ) } \\
\text { AUC stage } \mathrm{F} 3-\mathrm{F} 4>0.9\end{array}$ & $\begin{array}{l}\text { - Noninvasive tool for assessment of liver } \\
\text { fibrosis by measuring liver stiffness } \\
\text { - Immediate results } \\
\text { - Painless procedure } \\
\text { - Excellent performance in diagnosing severe } \\
\text { disease }\end{array}$ \\
\hline
\end{tabular}

Abbreviations: $\alpha 2-M C, \alpha 2$-macroglobulin; AST, aspartate aminotransferase; AUC, area under the curve; GT, glutamyl transpeptidase; HAl, histological activity score; $\mathrm{NASH}$, nonalcoholic steatohepatitis; HOMA-IR, homeostasis model assessment of insulin resistance.

The diagnostic performance of panel markers depends on the stage of fibrosis that is distinguished and disease origin. Although the diagnostic performance of the panel markers is broadly similar, there seems to be a trend of superior performance in alcohol-induced, followed by chronic HCV and nonalcoholic fatty liver disease, and then chronic HBV. In nonalcoholic fatty liver disease, a systematic review by Guha et al ${ }^{106}$ suggested that the evolution of noninvasive markers lagged behind HCV with fewer panel markers. Variables found to be significant in the detection of fibrosis included the presence of diabetes, age, homeostasis model assessment of insulin resistance, ratio of aspartate to alanine transaminase, decreased platelet count, presence of hyaluronic acid, and increased body mass index. However, it remains difficult to draw any firm conclusions regarding the performance of these markers, given the heterogeneous fibrosis scoring systems and endpoints used in these studies. Transient elastography could be useful as a screening test to exclude advanced fibrosis in patients with nonalcoholic fatty liver disease.

\section{Realistic endpoints for antifibrogenic therapy}

The most effective antifibrotic strategy is to cure the underlying disease process before advanced fibrosis has developed. Existing treatments, particularly those that treat the primary cause of tissue injury, can allow extensive resolution.

Advances in our understanding of the pathogenesis of liver fibrosis have identified several potential feasible therapeutic targets, but unfortunately clinical development so far has been disappointing. One major limitation has been the often-prolonged natural history of fibrosis compared with that in experimental models, and difficulties in accurate noninvasive fibrosis assessment, thus making clinical trial design difficult. Furthermore, many patients are asymptomatic even when fibrosis is already advanced, or present with decompensated cirrhosis, which would require not only prevention of evolution in cirrhosis but also reversal of established fibrosis in a cirrhotic liver. Indeed, in broad terms, the two main endpoints of antifibrogenic therapy are reduction of fibrogenesis in the precirrhotic stage, in order to prevent 
the establishment of cirrhosis, and reduction of fibrosis in a cirrhotic liver, leading to reduction of portal hypertension and expansion of the complication-free period (ie, compensated cirrhosis). Indeed, while the use of antifibrotic drugs in the precirrhotic stage is debatable and priority should be given to agents acting on the primary cause of disease (ie, antivirals), the single use of this class of drugs could be indicated in patients with cirrhosis, especially when not responding to treatments aimed at eliminating the cause of chronic damage. Several drugs with specific "antifibrotic activity" have been studied in human trials but were not shown to be clearly effective. The ideal antifibrotic agent which is safe when used over a long time, specific to the liver and nontoxic to hepatocytes, potent, orally bioavailable, and inexpensive, is not yet available. It is now well established that elimination of the fibrogenic stimulus can lead to regression of accumulated fibrosis, even in the setting of early cirrhosis. Examples include sustained virological clearance in $\mathrm{HCV}$ infection, ${ }^{107,108}$ durable viral suppression in patients with chronic HBV, ${ }^{109-111}$ venesection for hemochromatosis, ${ }^{112}$ chelation for Wilson's disease, immunosuppression for autoimmune hepatitis, ${ }^{113}$ and weight loss for nonalcoholic steatohepatitis. ${ }^{114}$ Unfortunately, curative therapy is not possible in many patients either because available diseasespecific therapies have failed or because of late presentation with established cirrhosis. These patients have limited therapeutic options to reduce their risk of developing complications from end-stage liver disease. Fortunately, a number of promising targeted approaches (Table 2) are in development. ${ }^{15}$ Such therapies have been targeted to any of several different biological targets (eg, inhibition of collagen synthesis, interruption of matrix deposition, stimulation of matrix degradation, modulation of stellate cell activation, induction of stellate cell death, or blocking receptor tyrosine kinases like vascular endothelial growth factor receptor and platelet-derived growth factor receptor).

In patients infected with $\mathrm{HBV}$ or $\mathrm{HCV}$, regression of liver fibrosis usually happens naturally upon achieving a sustained viral response from antiviral therapy. Controlling $\mathrm{HBV}$ involves giving the patient nucleotide analogs, such as lamivudine, adefovir, and entecavir, while combined pegylated IFN (+ribavirin) therapy provides the best treatment protocol for eradicating $\mathrm{HCV} .{ }^{116}$ Sustained response with this regimen has now reached $60 \%$. IFN may also regulate promoters of collagen gene expression and reduce hepatic stellate cell proliferation with the help of intracellular signaling molecules, like microRNA-29b. ${ }^{116-118}$

Therapeutics that target TIMP-1 provide a good strategy for antifibrotic development because TIMP-1 is implicated in extracellular collagen matrix turnover and antiapoptic

Table 2 Potential antifibrotic agents and mechanism of action $82,128,140$

\begin{tabular}{|c|c|c|}
\hline Compound & Target & Mechanism of action \\
\hline $\begin{array}{l}\text { Endothelin antagonist } \\
\text { A receptor antagonist (LUI 35252) }\end{array}$ & ET-I & $\begin{array}{l}\text { Inhibits HSC activation } \\
\text { and fibrogenesis }\end{array}$ \\
\hline $\begin{array}{l}\text { Angiotensin system inhibitors } \\
\text { Captopril, enalapril, perindopril; losartan, irbesartan, telmisartan }\end{array}$ & RAS & $\begin{array}{l}\text { Blocks profibrogenic effects } \\
\text { of angiotensin II }\end{array}$ \\
\hline $\begin{array}{l}\text { PPAR- } \gamma \\
\text { Glitazones (pioglitazone, rosiglitazone, troglitazone) }\end{array}$ & & Unknown \\
\hline $\begin{array}{l}\text { Anti-TGF- } \beta \\
\text { Anti-integrin } \alpha \varpi \beta 6 \text { antagonist (EMD405270), TGF- } \beta \\
\text { antisense oligonucleotides, soluble TGF- } \beta \text { decoy receptors }\end{array}$ & TGF- $\beta$ I & $\begin{array}{l}\text { Inhibits HSC fibrogenesis, } \\
\text { apoptosis }\end{array}$ \\
\hline Gliotoxin & HSC & Induces apoptosis \\
\hline $\begin{array}{l}\text { MMP-inducers } \\
\text { Halofuginone }\end{array}$ & Extracellular matrix & $\begin{array}{l}\text { Increase MMP fibrolytic } \\
\text { activity }\end{array}$ \\
\hline $\begin{array}{l}\text { TIMP inhibitor } \\
\text { Neutralizing anti-TIMP-I antibody }\end{array}$ & TIMP-I & Enhanced MMP activity \\
\hline Sulfasalazine & $\mathrm{NF}-\kappa \beta$ & Induce HSC apoptosis \\
\hline SiRNA & HSP47 & Induces matrix degradation \\
\hline Immunosuppressants & & \\
\hline $\begin{array}{l}\text { Mycophenolate mofetil, rapamycin } \\
\text { Angiogenesis inhibitors } \\
\text { VEGF receptor I and } 2 \text { antagonists (PTK, sorafenib, vatalanib), } \\
\text { anti-integrin } \alpha v \beta 3 \text { (EMD4099 I5) }\end{array}$ & & Inhibits HSC activation \\
\hline
\end{tabular}

Abbreviations: PPAR- $\gamma$, peroxisome proliferator-activated receptor-gamma; TGF- $\beta$, transforming growth factor beta; HSC, hepatic stellate cell/myofibroblast; MMP, matrix metalloproteinase; TIMP, tissue inhibitor of matrix metalloproteinase; HSP47, heat shock protein 47; VEGF, vascular endothelial growth factor; PTK, protein tyrosine kinase; NF, nuclear factor; ET-I, endothelin-I; RAS, renin-angiotensin system. 
activity towards myofibroblasts. ${ }^{63,79,119}$ Of experimental relevance, a recent study showed reduced collagen accumulation in fibrotic liver tissue of rats treated with a TIMP-1neutralizing antibody. ${ }^{120}$ Because agents targeting TIMP-1 act extracellularly, drug design does not have to overcome the additional burden of crossing membrane barriers in this case. ${ }^{79}$ Other agents that degrade the collagen-rich matrix may also offer alternative and viable antifibrotic treatment. As proof of concept, overexpression of matrix metalloproteinase 8 with adenovirus therapy led to fibrosis regression in two models of experimental liver fibrosis ( $\mathrm{CCl}_{4}$ and bile duct ligation). ${ }^{121}$ Adenoviral transfection of matrix metalloproteinase 1 similarly attenuated hepatic fibrosis in rats. ${ }^{122}$

Perhaps some of the most interesting drug targets stem from inhibition of transforming growth factor- $\beta 1$, because this cytokine plays a critical role in the activation of myofibroblasts. Adenoviral constructs involved in transforming growth factor- $\beta 1$ signaling and other soluble molecules that modulate the expression or function of transforming growth factor- $\beta 1$ have shown antifibrotic efficacy in vitro and in vivo. ${ }^{123-130}$ However, the importance of this cytokine in homeostasis and repair, cautions against the long-term use of transforming growth factor- $\beta 1$ inhibitors, making this class of therapeutics less attractive. Indeed, complete chronic abrogation of the effects of transforming growth factor- $\beta 1$ on immunomodulation and regulation of epithelial cell apoptosis could result in autoimmunity and the emergence of neoplastic clones.

Angiotensin II accelerates fibrogenesis in response to liver injury. Vasoactive modulators like angiotensin, type 1 receptor antagonists, or angiotensin-converting enzyme inhibitors therefore represent attractive antifibrotic therapies by blocking angiotensin II receptor access, or decreasing its production. ${ }^{125,126,131-134}$ Such agents have effectively attenuated liver fibrosis in rat models and are suitable for long-term treatment because of their known safety profile.

Targeted antifibrotic therapies that block receptors on hepatic stellate cells have emerged with promising results. Target specificity is achieved by modifying drug protein carriers with molecules that recognize growth factors and collagen type IV receptors, ${ }^{135}$ or by coupling apoptotic gliotoxin to mannose-6-phosphate-modified human serum albumin. ${ }^{136}$ Alternatively, Sato et al observed complete resolution of hepatic fibrosis in rats treated with siRNA delivered with high specificity to stellate cells using vitamin A-coupled liposomes. ${ }^{137}$

\section{Conclusion}

Our understanding of the mechanism of liver fibrosis has changed dramatically over the last decade. It is no longer viewed as passive or permanent, but as a dynamic process. Many mechanisms and potential therapies continue to be identified and more research is required. The number of potential therapeutic targets has exploded in recent years, and the realization that fibrosis can regress lends new urgency to their investigation. For the time being, greater emphasis must be placed on early identification of patients with potentially treatable chronic liver disease.

\section{Disclosure}

The authors report no conflicts of interest in this work.

\section{References}

1. Iredale JP. Cirrhosis: new research provides a basis for rational and targeted treatments. BMJ. 2003;327(7407):143-147.

2. Friedman SL. Molecular regulation of hepatic fibrosis, an integrated cellular response to tissue injury. J Biol Chem. 2000;275(4):2247-2250.

3. Fallowfield JA, Kendall TJ, Iredale JP. Reversal of fibrosis: no longer a pipe dream? Clin Liver Dis. 2006;10(3):481-497.

4. Iredale JP. Models of liver fibrosis: exploring the dynamic nature of inflammation and repair in a solid organ. J Clin Invest. 2007;117(3): 539-548.

5. Kinnman N, Francoz C, Barbu V, et al. The myofibroblastic conversion of peribiliary fibrogenic cells distinct from hepatic stellate cells is stimulated by platelet-derived growth factor during liver fibrogenesis. Lab Invest. 2003;83(2):163-173.

6. Kinnman N, Goria O, Wendum D, et al. Hepatic stellate cell proliferation is an early platelet-derived growth factor-mediated cellular event in rat cholestatic liver injury. Lab Invest. 2001;81(12): 1709-1716.

7. Maher JJ, McGuire RF. Extracellular matrix gene expression increases preferentially in rat lipocytes and sinusoidal endothelial cells during hepatic fibrosis in vivo. J Clin Invest. 1990;86(5):1641-1648.

8. Wong L, Yamasaki G, Johnson RJ, Friedman SL. Induction of beta-platelet-derived growth factor receptor in rat hepatic lipocytes during cellular activation in vivo and in culture. J Clin Invest. 1994;94(4): 1563-1569.

9. Choi SS, Syn WK, Karaca GF, et al. Leptin promotes the myofibroblastic phenotype in hepatic stellate cells by activating the hedgehog pathway. J Biol Chem . 2010;285(47):36551-36560.

10. Henderson NC, Mackinnon AC, Farnworth SL, et al. Galectin-3 regulates myofibroblast activation and hepatic fibrosis. Proc Natl Acad Sci U S A. 2006;103(13):5060-5065.

11. Beaussier M, Wendum D, Schiffer E, et al. Prominent contribution of portal mesenchymal cells to liver fibrosis in ischemic and obstructive cholestatic injuries. Lab Invest. 2007;87(3):292-303.

12. Russo FP, Alison MR, Bigger BW, et al. The bone marrow functionally contributes to liver fibrosis. Gastroenterology. 2006;130(6): 1807-1821.

13. Wallace K, Burt AD, Wright MC. Liver fibrosis. Biochem J. 2008; 411(1):1-18.

14. Pinzani M. Epithelial-mesenchymal transition in chronic liver disease: fibrogenesis or escape from death? J Hepatol. February 12, 2011. [Epub ahead of print].

15. Lin SL, Kisseleva T, Brenner DA, Duffield JS. Pericytes and perivascular fibroblasts are the primary source of collagen-producing cells in obstructive fibrosis of the kidney. Am J Pathol. 2008;173(6):1617-1627. 
16. Taura K, Miura K, Iwaisako K, et al. Hepatocytes do not undergo epithelial-mesenchymal transition in liver fibrosis in mice. Hepatology. 2010;51(3):1027-1036.

17. Pilling D, Fan T, Huang D, Kaul B, Gomer RH. Identification of markers that distinguish monocyte-derived fibrocytes from monocytes, macrophages, and fibroblasts. PLoS One. 2009;4(10):e7475.

18. Humphreys BD, Lin SL, Kobayashi A, et al. Fate tracing reveals the pericyte and not epithelial origin of myofibroblasts in kidney fibrosis. Am J Pathol. 2010;176(1):85-97.

19. Ng YY, Fan JM, Mu W, et al. Glomerular epithelial-myofibroblast transdifferentiation in the evolution of glomerular crescent formation. Nephrol Dial Transplant. 1999;14(12):2860-2872.

20. Fan JM, Ng YY, Hill PA, et al. Transforming growth factor-beta regulates tubular epithelial-myofibroblast transdifferentiation in vitro. Kidney Int. 1999;56(4):1455-1467.

21. Gershengorn MC, Hardikar AA, Wei C, Geras-Raaka E, Marcus-Samuels B, Raaka BM. Epithelial-to-mesenchymal transition generates proliferative human islet precursor cells. Science. 2004; 306(5705):2261-2264.

22. Kaimori A, Potter J, Kaimori JY, Wang C, Mezey E, Koteish A. Transforming growth factor-beta1 induces an epithelial-to-mesenchymal transition state in mouse hepatocytes in vitro. J Biol Chem. 2007; 282(30):22089-22101.

23. Russ HA, Ravassard P, Kerr-Conte J, Pattou F, Efrat S. Epithelialmesenchymal transition in cells expanded in vitro from lineage-traced adult human pancreatic beta cells. PLoS One. 2009;4(7):e6417.

24. Godoy P, Hengstler JG, Ilkavets I, et al. Extracellular matrix modulates sensitivity of hepatocytes to fibroblastoid dedifferentiation and transforming growth factor beta-induced apoptosis. Hepatology. 2009;49(6):2031-2043.

25. Strutz F, Okada H, Lo CW, et al. Identification and characterization of a fibroblast marker: FSP1. J Cell Biol. 1995;130(2):393-405.

26. Schneider M, Hansen JL, Sheikh SP. S100A4: a common mediator of epithelial-mesenchymal transition, fibrosis and regeneration in diseases? J Mol Med. 2008;86(5):507-522.

27. Le Hir M, Hegyi I, Cueni-Loffing D, Loffing J, Kaissling B. Characterization of renal interstitial fibroblast-specific protein 1/S100A4positive cells in healthy and inflamed rodent kidneys. Histochem Cell Biol. 2005;123(4-5):335-346.

28. Inoue T, Plieth D, Venkov CD, Xu C, Neilson EG. Antibodies against macrophages that overlap in specificity with fibroblasts. Kidney Int. 2005;67(6):2488-2493.

29. Omenetti A, Porrello A, Jung Y, et al. Hedgehog signaling regulates epithelial-mesenchymal transition during biliary fibrosis in rodents and humans. J Clin Invest. 2008;118(10):3331-3342.

30. Rygiel KA, Robertson H, Marshall HL, et al. Epithelial-mesenchymal transition contributes to portal tract fibrogenesis during human chronic liver disease. Lab Invest. 2008;88(2):112-123.

31. Diaz R, Kim JW, Hui JJ, et al. Evidence for the epithelial to mesenchymal transition in biliary atresia fibrosis. Hum Pathol. 2008; 39(1):102-115.

32. Scholten D, Osterreicher CH, Scholten A, et al. Genetic labeling does not detect epithelial-to-mesenchymal transition of cholangiocytes in liver fibrosis in mice. Gastroenterology. 2010;139(3):987-998.

33. Bataller R, North KE, Brenner DA. Genetic polymorphisms and the progression of liver fibrosis: a critical appraisal. Hepatology. 2003; 37(3):493-503.

34. Kral JG, Thung SN, Biron S, et al. Effects of surgical treatment of the metabolic syndrome on liver fibrosis and cirrhosis. Surgery. 2004; 135(1):48-58.

35. Kweon YO, Goodman ZD, Dienstag JL, et al. Decreasing fibrogenesis: an immunohistochemical study of paired liver biopsies following lamivudine therapy for chronic hepatitis B. J Hepatol. 2001; 35(6):749-755.

36. Poynard T, Imbert-Bismut F, Ratziu V, et al. Biochemical markers of liver fibrosis in patients infected by hepatitis $\mathrm{C}$ virus: longitudinal validation in a randomized trial. J Viral Hepat. 2002;9(2):128-133.
37. de Torres M, Poynard T. Risk factors for liver fibrosis progression in patients with chronic hepatitis C. Ann Hepatol. 2003;2(1):5-11.

38. Wiley TE, McCarthy M, Breidi L, Layden TJ. Impact of alcohol on the histological and clinical progression of hepatitis $\mathrm{C}$ infection. Hepatology. 1998;28(3):805-809.

39. Benhamou Y, Bochet M, Di Martino V, et al. Liver fibrosis progression in human immunodeficiency virus and hepatitis $\mathrm{C}$ virus coinfected patients. The Multivirc Group. Hepatology. 1999;30(4):1054-1058.

40. Bissell DM. Sex and hepatic fibrosis. Hepatology. 1999;29(3):988-989.

41. Deuffic S, Buffat L, Poynard T, Valleron AJ. Modeling the hepatitis C virus epidemic in France. Hepatology. 1999;29(5):1596-1601.

42. Massard J, Ratziu V, Thabut D, et al. Natural history and predictors of disease severity in chronic hepatitis C. J Hepatol. 2006; 44(Suppl 1):S19-S24

43. Poynard T, Bedossa P, Opolon P. Natural history of liver fibrosis progression in patients with chronic hepatitis C. The OBSVIRC, METAVIR, CLINIVIR, and DOSVIRC groups. Lancet. 1997;349(9055): 825-832.

44. Di Martino V, Lebray P, Myers RP, et al. Progression of liver fibrosis in women infected with hepatitis $\mathrm{C}$ : long-term benefit of estrogen exposure. Hepatology. 2004;40(6):1426-1433.

45. Mohamed HR, Abdel-Azziz MY, Zalata KR, Abdel-Razik AM. Relation of insulin resistance and liver fibrosis progression in patients with chronic hepatitis C virus infection. Int J Health Sci (Qassim). 2009;3(2): 177-186.

46. Berenguer J, Bellon JM, Miralles P, et al. Association between exposure to nevirapine and reduced liver fibrosis progression in patients with HIV and hepatitis C virus coinfection. Clin Infect Dis. 2008;46(1): 137-143.

47. Martinez-Sierra C, Arizcorreta A, Diaz F, et al. Progression of chronic hepatitis $\mathrm{C}$ to liver fibrosis and cirrhosis in patients coinfected with hepatitis $\mathrm{C}$ virus and human immunodeficiency virus. Clin Infect Dis. 2003;36(4):491-498.

48. Qurishi N, Kreuzberg C, Luchters G, et al. Effect of antiretroviral therapy on liver-related mortality in patients with HIV and hepatitis C virus coinfection. Lancet. 2003;362(9397):1708-1713.

49. Merchante N, Giron-Gonzalez JA, Gonzalez-Serrano M, et al. Survival and prognostic factors of HIV-infected patients with HCV-related endstage liver disease. AIDS. 2006;20(1):49-57.

50. Ragni MV, Belle SH. Impact of human immunodeficiency virus infection on progression to end-stage liver disease in individuals with hemophilia and hepatitis C virus infection. J Infect Dis. 2001;183(7): 1112-1115.

51. Propst A, Propst T, Judmaier G, Vogel W. Prognosis in nonalcoholic steatohepatitis. Gastroenterology. 1995;108(5):1607.

52. Argo CK, Northup PG, Al-Osaimi AM, Caldwell SH. Systematic review of risk factors for fibrosis progression in non-alcoholic steatohepatitis. J Hepatol. 2009;51(2):371-379.

53. Wood MJ, Powell LW, Ramm GA. Environmental and genetic modifiers of the progression to fibrosis and cirrhosis in hemochromatosis. Blood. 2008;111(9):4456-4462.

54. Powell LW, Dixon JL, Ramm GA, et al. Screening for hemochromatosis in asymptomatic subjects with or without a family history. Arch Intern Med. 2006;166(3):294-301.

55. Bacon BR, Olynyk JK, Brunt EM, Britton RS, Wolff RK. HFE genotype in patients with hemochromatosis and other liver diseases. Ann Intern Med. 1999;130(12):953-962.

56. Poynard T, McHutchison J, Manns M, et al. Impact of pegylated interferon alfa-2b and ribavirin on liver fibrosis in patients with chronic hepatitis C. Gastroenterology. 2002;122(5):1303-1313.

57. Gieling RG, Burt AD, Mann DA. Fibrosis and cirrhosis reversibility - molecular mechanisms. Clin Liver Dis. 2008;12(4): 915-937.

58. Issa R, Zhou X, Constandinou CM, et al. Spontaneous recovery from micronodular cirrhosis: evidence for incomplete resolution associated with matrix cross-linking. Gastroenterology. 2004;126(7): 1795-1808. 
59. Iredale JP, Benyon RC, Pickering J, et al. Mechanisms of spontaneous resolution of rat liver fibrosis. Hepatic stellate cell apoptosis and reduced hepatic expression of metalloproteinase inhibitors. J Clin Invest. 1998;102(3):538-549.

60. Watanabe T, Niioka M, Hozawa S, et al. Gene expression of interstitial collagenase in both progressive and recovery phase of rat liver fibrosis induced by carbon tetrachloride. J Hepatol. 2000;33(2):224-235.

61. Elsharkawy AM, Oakley F, Mann DA. The role and regulation of hepatic stellate cell apoptosis in reversal of liver fibrosis. Apoptosis. 2005;10(5):927-939.

62. Massarrat S, Fallahazad V, Kamalian N. Clinical, biochemical and imaging-verified regression of hepatitis B-induced cirrhosis. Liver Int. 2004;24(2):105-109.

63. Murphy FR, Issa R, Zhou X, et al. Inhibition of apoptosis of activated hepatic stellate cells by tissue inhibitor of metalloproteinase- 1 is mediated via effects on matrix metalloproteinase inhibition: implications for reversibility of liver fibrosis. J Biol Chem. 2002;277(13): 11069-11076.

64. Sohara N, Znoyko I, Levy MT, Trojanowska M, Reuben A. Reversal of activation of human myofibroblast-like cells by culture on a basement membrane-like substrate. J Hepatol. 2002;37(2):214-221.

65. Hazra S, Miyahara T, Rippe RA, Tsukamoto H. PPAR gamma and hepatic stellate cells. Comp Hepatol. 2004;3 (Suppl 1):S7.

66. Kim WH, Matsumoto K, Bessho K, Nakamura T. Growth inhibition and apoptosis in liver myofibroblasts promoted by hepatocyte growth factor leads to resolution from liver cirrhosis. Am J Pathol. 2005;166(4): 1017-1028.

67. Issa $\mathrm{R}$, Zhou $\mathrm{X}$, Trim $\mathrm{N}$, et al. Mutation in collagen-1 that confers resistance to the action of collagenase results in failure of recovery from CCl4-induced liver fibrosis, persistence of activated hepatic stellate cells, and diminished hepatocyte regeneration. FASEB J. 2003; 17(1):47-49.

68. Novo E, Marra F, Zamara E, et al. Overexpression of Bcl-2 by activated human hepatic stellate cells: resistance to apoptosis as a mechanism of progressive hepatic fibrogenesis in humans. Gut. 2006; 55(8):1174-1182.

69. Pinzani M. Unraveling the spider web of hepatic stellate cell apoptosis. Gastroenterology. 2009;136(7):2061-2063.

70. Duffield JS, Forbes SJ, Constandinou CM, et al. Selective depletion of macrophages reveals distinct, opposing roles during liver injury and repair. J Clin Invest. 2005;115(1):56-65.

71. Fallowfield JA, Mizuno M, Kendall TJ, et al. Scar-associated macrophages are a major source of hepatic matrix metalloproteinase-13 and facilitate the resolution of murine hepatic fibrosis. J Immunol. 2007; 178(8):5288-5295.

72. Mitchell C, Couton D, Couty JP, et al. Dual role of CCR2 in the constitution and the resolution of liver fibrosis in mice. Am J Pathol. 2009; 174(5):1766-1775

73. Desmet VJ, Roskams T. Reversal of cirrhosis: evidence-based medicine? Gastroenterology. 2003;125(2):629-630.

74. Desmet VJ, Roskams T. Cirrhosis reversal: a duel between dogma and myth. J Hepatol. 2004;40(5):860-867.

75. Poynard T, McHutchison J, Davis GL, et al. Impact of interferon alfa-2b and ribavirin on progression of liver fibrosis in patients with chronic hepatitis C. Hepatology. 2000;32(5):1131-1137.

76. Serpaggi J, Carnot F, Nalpas B, et al. Direct and indirect evidence for the reversibility of cirrhosis. Hum Pathol. 2006;37(12): 1519-1526.

77. Bortolotti F, Guido M. Reversal of liver cirrhosis: a desirable clinical outcome and its pathogenic background. J Pediatr Gastroenterol Nutr. 2007;44(4):401-406

78. Goodman ZD, Ishak KG. Occlusive venous lesions in alcoholic liver disease. A study of 200 cases. Gastroenterology. 1982;83(4): 786-796.

79. Muddu AK, Guha IN, Elsharkawy AM, Mann DA. Resolving fibrosis in the diseased liver: translating the scientific promise to the clinic. Int J Biochem Cell Biol. 2007;39(4):695-714.
80. Pinzani M, Rombouts K. Liver fibrosis: from the bench to clinical targets. Dig Liver Dis. 2004;36(4):231-242.

81. Castera L, Pinzani M. Biopsy and non-invasive methods for the diagnosis of liver fibrosis: does it take two to tango? Gut. 2010;59(7): 861-866.

82. Bedossa P, Dargere D, Paradis V. Sampling variability of liver fibrosis in chronic hepatitis C. Hepatology. 2003;38(6):1449-1457.

83. Regev A, Berho M, Jeffers LJ, et al. Sampling error and intraobserver variation in liver biopsy in patients with chronic HCV infection. Am J Gastroenterol. 2002;97(10):2614-2618.

84. Goodman ZD, Stoddard AM, Bonkovsky HL, et al. Fibrosis progression in chronic hepatitis $\mathrm{C}$ : morphometric image analysis in the HALT-C trial. Hepatology. 2009;50(6):1738-1749.

85. Rousselet MC, Michalak S, Dupre F, et al. Sources of variability in histological scoring of chronic viral hepatitis. Hepatology. 2005;41(2): 257-264.

86. Marcellin P, Asselah T, Boyer N. Fibrosis and disease progression in hepatitis C. Hepatology. 2002;36(5 Suppl 1):S47-S56.

87. Patel K. Noninvasive tools to assess liver disease. Curr Opin Gastroenterol. 2010;26(3):227-233.

88. Castera L, Forns X, Alberti A. Non-invasive evaluation of liver fibrosis using transient elastography. J Hepatol. 2008;48(5): $835-847$.

89. Wai CT, Greenson JK, Fontana RJ, et al. A simple noninvasive index can predict both significant fibrosis and cirrhosis in patients with chronic hepatitis C. Hepatology. 2003;38(2):518-526.

90. Pinzani M, Vizzutti F, Arena U, Marra F. Technology insight: noninvasive assessment of liver fibrosis by biochemical scores and elastography. Nat Clin Pract Gastroenterol Hepatol. 2008;5(2): 95-106.

91. Kelleher TB, Mehta SH, Bhaskar R, et al. Prediction of hepatic fibrosis in $\mathrm{HIV} / \mathrm{HCV}$ co-infected patients using serum fibrosis markers: the SHASTA index. J Hepatol. 2005;43(1):78-84.

92. Lieber CS, Weiss DG, Morgan TR, Paronetto F. Aspartate aminotransferase to platelet ratio index in patients with alcoholic liver fibrosis Am J Gastroenterol. 2006;101(7):1500-1508.

93. Shaheen AA, Myers RP. Diagnostic accuracy of the aspartate aminotransferase-to-platelet ratio index for the prediction of hepatitis C-related fibrosis: a systematic review. Hepatology. 2007;46(3): 912-921.

94. Forns X, Ampurdanes S, Llovet JM, et al. Identification of chronic hepatitis $\mathrm{C}$ patients without hepatic fibrosis by a simple predictive model. Hepatology. 2002;36(4 Pt 1):986-992.

95. Rosenberg WM, Voelker M, Thiel R, et al. Serum markers detect the presence of liver fibrosis: a cohort study. Gastroenterology. 2004; 127(6):1704-1713.

96. Patel K, Gordon SC, Jacobson I, et al. Evaluation of a panel of non-invasive serum markers to differentiate mild from moderate-toadvanced liver fibrosis in chronic hepatitis C patients. J Hepatol. 2004; 41(6):935-942.

97. Parkes J, Guha IN, Roderick P, Rosenberg W. Performance of serum marker panels for liver fibrosis in chronic hepatitis C. J Hepatol. 2006; 44(3):462-474

98. Castera L, Bedossa P. How to assess liver fibrosis in chronic hepatitis C: serum markers or transient elastography vs liver biopsy? Liver Int. 2011;31 (Suppl 1):13-17.

99. Sandrin L, Fourquet B, Hasquenoph JM, et al. Transient elastography: a new noninvasive method for assessment of hepatic fibrosis. Ultrasound Med Biol. 2003;29(12):1705-1713.

100. Castera L, Foucher J, Bernard PH, et al. Pitfalls of liver stiffness measurement: a 5-year prospective study of 13,369 examinations. Hepatology. 2010;51(3):828-835.

101. Coco B, Oliveri F, Maina AM, et al. Transient elastography: a new surrogate marker of liver fibrosis influenced by major changes of transaminases. J Viral Hepat. 2007;14(5):360-369.

102. Sagir A, Erhardt A, Schmitt M, Haussinger D. Transient elastography is unreliable for detection of cirrhosis in patients with acute liver damage. Hepatology. 2008;47(2):592-595. 
103. Arena U, Vizzutti F, Corti G, et al. Acute viral hepatitis increases liver stiffness values measured by transient elastography. Hepatology. 2008:47(2):380-384.

104. Millonig G, Reimann FM, Friedrich S, et al. Extrahepatic cholestasis increases liver stiffness (FibroScan) irrespective of fibrosis. Hepatology. 2008;48(5):1718-1723.

105. Millonig G, Friedrich S, Adolf S, et al. Liver stiffness is directly influenced by central venous pressure. J Hepatol. 2010;52(2):206-210.

106. Guha IN, Parkes J, Roderick PR, Harris S, Rosenberg WM. Non-invasive markers associated with liver fibrosis in non-alcoholic fatty liver disease. Gut. 2006;55(11):1650-1660.

107. Bruno S, Stroffolini T, Colombo M, et al. Sustained virological response to interferon-alpha is associated with improved outcome in HCV-related cirrhosis: a retrospective study. Hepatology. 2007;45(3): 579-587.

108. Veldt BJ, Heathcote EJ, Wedemeyer H, et al. Sustained virologic response and clinical outcomes in patients with chronic hepatitis $\mathrm{C}$ and advanced fibrosis. Ann Intern Med. 2007;147(10):677-684.

109. Dienstag JL, Schiff ER, Wright TL, et al. Lamivudine as initial treatment for chronic hepatitis B in the United States. N Engl J Med. 1999;341(17):1256-1263.

110. Hadziyannis SJ, Tassopoulos NC, Heathcote EJ, et al. Long-term therapy with adefovir dipivoxil for $\mathrm{HBeAg-negative} \mathrm{chronic} \mathrm{hepatitis}$ B for up to 5 years. Gastroenterology. 2006;131(6):1743-1751.

111. Dienstag JL, Goldin RD, Heathcote EJ, et al. Histological outcome during long-term lamivudine therapy. Gastroenterology. 2003;124(1): 105-117.

112. Falize L, Guillygomarch A, Perrin M, et al. Reversibility of hepatic fibrosis in treated genetic hemochromatosis: a study of 36 cases. Hepatology. 2006;44(2):472-477.

113. Cotler SJ, Jakate S, Jensen DM. Resolution of cirrhosis in autoimmune hepatitis with corticosteroid therapy. J Clin Gastroenterol. 2001;32(5): 428-430.

114. Mummadi RR, Kasturi KS, Chennareddygari S, Sood GK. Effect of bariatric surgery on nonalcoholic fatty liver disease: systematic review and meta-analysis. Clin Gastroenterol Hepatol. 2008;6(12):1396-1402.

115. Thompson AJ, Patel K. Antifibrotic therap ies: will we ever get there? Curr Gastroenterol Rep. 2010;12(1):23-29.

116. Kawada N. Evolution of hepatic fibrosis research. Hepatol Res. 2011; 41(3):199-208.

117. Sekiya Y, Ogawa T, Iizuka M, Yoshizato K, Ikeda K, Kawada N. Downregulation of cyclin E1 expression by microRNA-195 accounts for interferon-beta-induced inhibition of hepatic stellate cell proliferation. $J$ Cell Physiol. December 29, 2010. [Epub ahead of print].

118. Ogawa T, Iizuka M, Sekiya Y, Yoshizato K, Ikeda K, Kawada N. Suppression of type I collagen production by microRNA-29b in cultured human stellate cells. Biochem Biophys Res Commun. 2010; 391(1):316-321.

119. Iredale JP. Tissue inhibitors of metalloproteinases in liver fibrosis. Int J Biochem Cell Biol. 1997;29(1):43-54.

120. Parsons CJ, Bradford BU, Pan CQ, et al. Antifibrotic effects of a tissue inhibitor of metalloproteinase-1 antibody on established liver fibrosis in rats. Hepatology. 2004;40(5):1106-1115.

121. Siller-Lopez F, Sandoval A, Salgado S, et al. Treatment with human metalloproteinase- 8 gene delivery ameliorates experimental rat liver cirrhosis. Gastroenterology. 2004;126(4):1122-1133.

122. Iimuro Y, Nishio T, Morimoto T, et al. Delivery of matrix metalloproteinase-1 attenuates established liver fibrosis in the rat. Gastroenterology. 2003;124(2):445-448.

Hepatic Medicine: Evidence and Research

\section{Publish your work in this journal}

Hepatic Medicine: Evidence and Research is an international, peerreviewed, open access journal covering all aspects of adult and pediatric hepatology in the clinic and laboratory including the following topics: Pathology, pathophysiology of hepatic disease; Investigation and treatment of hepatic disease; Pharmacology of drugs used for
123. Yata Y, Gotwals P, Koteliansky V, Rockey DC. Dose-dependent inhibition of hepatic fibrosis in mice by a TGF-beta soluble receptor: implications for antifibrotic therapy. Hepatology. 2002;35(5): 1022-1030.

124. George J, Roulot D, Koteliansky VE, Bissell DM. In vivo inhibition of rat stellate cell activation by soluble transforming growth factor beta type II receptor: a potential new therapy for hepatic fibrosis. Proc Natl Acad Sci U S A. 1999;96(22):12719-12724.

125. Schuppan D, Popov Y. Rationale and targets for antifibrotic therapies. Gastroenterol Clin Biol. 2009;33(10-11):949-957.

126. Kisseleva T, Brenner DA. Anti-fibrogenic strategies and the regression of fibrosis. Best Pract Res Clin Gastroenterol. 2011;25(2):305-317.

127. Subeq YM, Ke CY, Lin NT, Lee CJ, Chiu YH, Hsu BG. Valsartan decreases TGF-beta1 production and protects against chlorhexidine digluconate-induced liver peritoneal fibrosis in rats. Cytokine. 2011; 53(2):223-230.

128. He H, Mennone A, Boyer JL, Cai SY. Combination of retinoic acid and ursodeoxycholic acid attenuates liver injury in bile duct-ligated rats and human hepatic cells. Hepatology. 2011;53(2):548-557.

129. Szuster-Ciesielska A, Plewka K, Daniluk J, Kandefer-Szerszen M. Betulin and betulinic acid attenuate ethanol-induced liver stellate cell activation by inhibiting reactive oxygen species (ROS), cytokine (TNF-alpha, TGF-beta) production and by influencing intracellular signaling. Toxicology. 2011;280(3):152-163.

130. Liu Y, Wang Z, Kwong SQ, et al. Inhibition of PDGF, TGF-beta, and Abl signaling and reduction of liver fibrosis by the small molecule Bcr-Abl tyrosine kinase antagonist Nilotinib. J Hepatol. January 18, 2011. [Epub ahead of print].

131. Yokohama S, Yoneda M, Haneda M, et al. Therapeutic efficacy of an angiotensin II receptor antagonist in patients with nonalcoholic steatohepatitis. Hepatology. 2004;40(5):1222-1225.

132. Croquet V, Moal F, Veal N, et al. Hemodynamic and antifibrotic effects of losartan in rats with liver fibrosis and/or portal hypertension. J Hepatol. 2002;37(6):773-780.

133. Moreno M, Bataller R. Cytokines and renin-angiotensin system signaling in hepatic fibrosis. Clin Liver Dis. 2008;12(4):825-852.

134. Paizis G, Gilbert RE, Cooper ME, et al. Effect of angiotensin II type 1 receptor blockade on experimental hepatic fibrogenesis. $J$ Hepatol. 2001;35(3):376-385.

135. Douglass A, Wallace K, Parr R, et al. Antibody-targeted myofibroblast apoptosis reduces fibrosis during sustained liver injury. J Hepatol. 2008;49(1):88-98.

136. Hagens WI, Beljaars L, Mann DA, et al. Cellular targeting of the apoptosis-inducing compound gliotoxin to fibrotic rat livers. J Pharmacol Exp Ther. 2008;324(3):902-910.

137. Sato Y, Murase K, Kato J, et al. Resolution of liver cirrhosis using vitamin A-coupled liposomes to deliver siRNA against a collagenspecific chaperone. Nat Biotechnol. 2008;26(4):431-442.

138. Marcellin P, Ziol M, Bedossa P, et al. Non-invasive assessment of liver fibrosis by stiffness measurement in patients with chronic hepatitis B. Liver Int. 2009;29(2):242-247.

139. Goodman ZD. Grading and staging systems for inflammation and fibrosis in chronic liver diseases. J Hepatol. 2007;47(4):598-607.

140. Strader DB, Wright T, Thomas DL, Seeff LB. Diagnosis, management, and treatment of hepatitis C. Hepatology. 2004;39(4):1147-1171.

Submit your manuscript here: http://www.dovepress.com/hepatic-medicine-evidence-and-research-journal

the treatment of hepatic disease. Issues of patient safety and quality of care will also be considered. The manuscript management system is completely online and includes a very quick and fair peer-review system, which is all easy to use. Visit http://www.dovepress.com/ testimonials.php to read real quotes from published authors. 